\title{
Research on Design Method of Children's Teaching Assisted Toys Based on STEAM Education
}

\author{
Lijuan Lang \\ School of Design, Beijing Normal University, Zhuhai, China \\ Email:1lj_851004@163.com
}

How to cite this paper: Lang, L. J. (2021). Research on Design Method of Children's Teaching Assisted Toys Based on STEAM Education. Open Journal of Social Sciences, 9, 628-635.

https://doi.org/10.4236/jss.2021.99046

Received: July 19, 2021

Accepted: September 26, 2021

Published: September 29, 2021

\begin{abstract}
During winter and summer vacations, parents are busy with work and have less time to accompany their children. Parents pay more and more attention to children's independent learning. Therefore, it is particularly important to cultivate children's self-learning ability. As an indispensable prop in the process of children's growth, teaching toys play a positive role in children's forming good habits and building up self-confidence. This article is based on STEAM education concept, through the analysis of the characteristics of existing auxiliary teaching toys, starting from the psychological and behavioral characteristics of children and parents, analyze their demand for auxiliary teaching toys, summarizes the design principle of auxiliary teaching toys, puts forward the design method of the auxiliary teaching toys, provide a reference for toy designers and children's education.
\end{abstract}

\section{Keywords}

STEAM Education, Teaching Assisted Toys, Design Principles, Design Methods

\section{Preface}

Against the background of the epidemic, training institutions are no longer popular. During winter and summer vacations, the most troublesome problem for parents is their children's study. Children are alone at home and parents are busy with work, so they have less time to accompany their children and cannot take into account their children's study. In the critical period of children's growth and development, the lack of reasonable education methods will affect children's personality development and habit formation. At the present stage, children's demand for toys is no longer just to meet the simple play, parents in 
the purchase of toys, but also gradually began to pay attention to the impact of toys on children's psychology and behavior; Secondly, the playability, interest and education of toys also become the main issues of concern to parents. Based on the analysis of the status quo of STEAM teaching assisted toys and the needs of children and parents for toys, this paper proposes the design method for STEAM teaching assisted toys, hoping to provide a reference direction for the development of children's teaching AIDS and teaching Assisted toys STEAM education.

\section{STEAM Education}

STEAM education is a comprehensive education that integrates science, technology, engineering, art and mathematics (Liu, 2020). STEAM is an educational concept that integrates Science, Technology, Engineering, Arts and Mathematics into an interdisciplinary integrated education model. STEAM on cross-border education concept, focusing on practice, compared with the traditional teaching concept, STEAM education pays more attention to cultivate compound talents, their ability to think independently, from the perspective of hands-on practice and thinking training, the ascending children found the problem, problem-solving ability, will exert positive effects on children's creative ability.

Steam teaching assisted toys are adapted from this educational philosophy by incorporating a variety of learning systems into traditional toys. STEAM education emphasizes the educational mode of "learning by doing" and "doing while learning", so that children can experience the joy of hands-on creation. Designers can combine the ideas of STEAM education in the design process to make toys more playable and intelligent while meeting the basic requirements (Qin et al., 2020). So as to cultivate children's comprehensive literacy, promote the development of children's cognitive ability, motor ability, emotional ability and other skills.

\section{Current Status of STEAM Educational Toys}

Social competition is gradually increasing, and parents feel great pressure in education. Influenced by the epidemic, more families choose to let their children study at home during winter and summer vacations. As parents are busy with work, they have no time to accompany their children, which increases the demand for teaching-assisted toys. Steam toys can transform difficult knowledge into fun games, thus responding to the diversified development of education, and are deeply loved by children.

In terms of the STEAM teaching Assisted toys market, it can be roughly divided into two categories. One is programming toys based on LEGO, which can be freely splintered through many modules and combined with programming to cultivate children's practical ability and logic ability; the other type is the robot human represented by DFrobot, which is a kind of educational toy with the function of learning and accompanying, and parents can communicate with their children through the robot. Different from traditional toys and teaching 
AIDS, there is no obvious dividing line between toys and teaching AIDS for STEAM education concept. Toys can be used as the carrier of STEAM education concept to help children play and learn more efficiently, conveniently and interestingly, and cultivate children's innovation consciousness.

\section{Design Principles for STEAM Educational Toys}

Good toys can help children develop good study habits, interpersonal communication, concentration and so on. The educational purpose of STEAM teaching Assisted toys is to enable children to play while contributing to the development of children's intelligence and ability. Therefore, STEAM teaching Assisted toys should be designed to meet the needs of children while focusing on the bottom line of parents.

\subsection{Play and Learn}

STEAM teaching Assisted toys should be both playful and educational, learning knowledge in a playful way by combining traditional teaching principles with toys, For example, physics, chemistry, mathematics, nature and other knowledge can be visualized and standardized through teaching-assisted toys. Children of different ages can be classified according to the degree of difficulty. Based on this, children's creativity can be stimulated, and their basic hands-on ability can be cultivated; in addition, by observing the external characteristics of things around, such as color, size, shape, to promote the development of children's observation and imagination.

\subsection{Development and Cognition}

According to the psychological needs and behavioral characteristics of children of different ages, corresponding teaching toys are designed (Figure 1). 0 - $36 \mathrm{M}$,

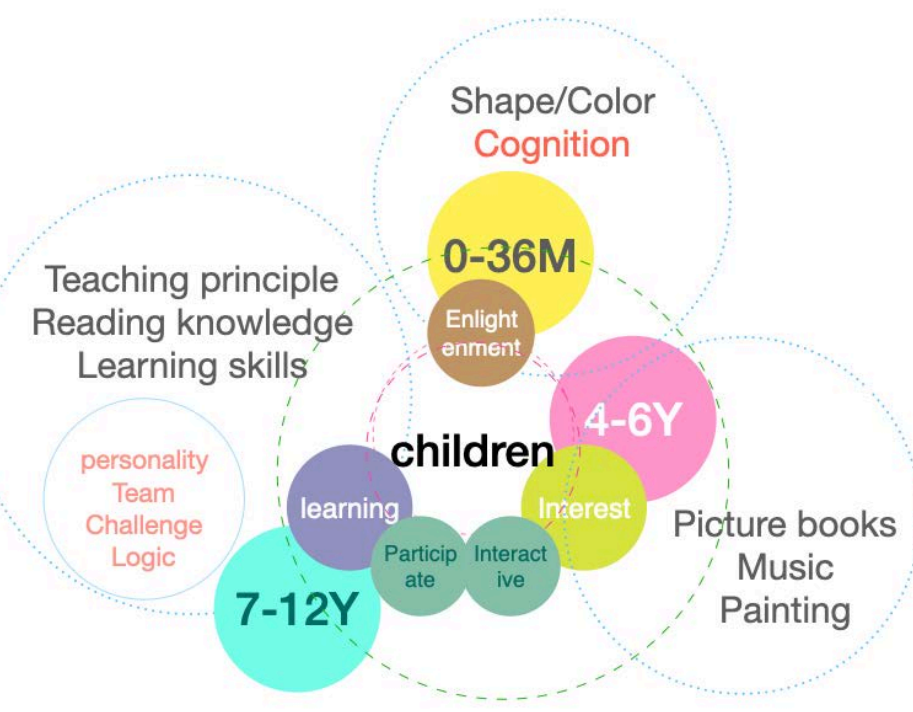

Figure 1. Characteristics of toys of different ages. 
children's own coordination ability, vision, hearing and touch gradually develop, and their cognition of things is initially established. Their desire for communication and curiosity are constantly enhanced. At this stage, children's teaching-assisted toys are mainly reflected in their cognition through shape, color and other information. $4-6 \mathrm{Y}$ is the language outbreak period of children. At this stage, children can play independently and enjoy themselves, but they are possessive. Teaching Assisted toys are mostly presented in the form of picture books, music, painting, etc. Toys to communicate with parents and students in the process of interaction, to improve the interactivity between children and parents, partners, and engaged and exert a subtle influence on cultivating children's sharing, collaboration, communication and so on a series of good habits, to cultivate children's interpersonal skills and team cooperation ability, and gain a sense of achievement; $7-12 \mathrm{Y}$ belongs to the primary school education stage. Children at this stage have the spirit of adventure, like group activities, and can actively abide by the rules of the game. Therefore, toys with personalized, teamwork, challenging and logical characteristics are more suitable for this growth stage. In addition, the toy should be designed and positioned in accordance with the school environment.

\subsection{Purchase and Use}

In the process of the growth and development of children, parents accompany is indispensable, parents as a buyer, they will not allow to ignore, parents hope children can acquire knowledge in the play, the growth of the ability, through the dominant way to see the children change (Song \& Jiang, 2020). Therefore, in meeting the demand of children's toys at the same time, can let parents to participate in some common finish operation, Will greatly enhance the interaction between children and their parents; Secondly, parents pay more and more attention to the function and significance of toys in the process of choosing toys, hoping that toys can promote children's physical movement, language, cognition and social development (Yang et al., 2014). Parents hope that children can gain positive guidance and improve their abilities through play.

\section{Design Method of STEAM Teaching Auxiliary Toys}

\subsection{Thematic Design}

The traditional course teaching method is mainly based on textbooks and theoretical knowledge, which makes it difficult for children to understand and apply knowledge into practice, children's understanding of things is mainly through continuous exploration and experience. STEAM teaching assisted toys to science, technology, engineering, art, mathematics, five aspects of knowledge, in the form of theme into toy design, and through the interesting way to convey information, to let children to deepen the understanding of classroom knowledge, consolidate the diversification of subject contents, so as to cultivate their learning initiative, help children develop intelligence, wisdom, to better tap the potential 
of children.

Figure 2 eliminates ball teaching toys, using different colors and colors of the ball, children through the use of operational tools hands-on practice, cultivate children's thinking ability and observation, help children to maintain concentration, improve memory, so as to improve their academic performance and strengthen the cultivation of children's self-confidence.

\subsection{Interactive Design}

Good toys should help children develop healthy interpersonal relationships and interact with others happily. Therefore, the design of "gamified" toys that can reflect "playmate participation" and "life situation" is an inevitable trend in today's toy design ( $\mathrm{Yu}, 2016)$. Therefore, it is particularly important to pay attention to the communication and interaction between parents and children, toys and children and children. Interactive toys can be used as a link to pass information to children and parents, play and learn together with children, and enhance children's emotional experience.

\subsection{Structural Exploration}

Existing teaching toys, such as disk splicing toys, Lego toys are made by the combination of modular assembly in the form of structure between the parts can affect the stability in the process of assembling, interoperability, supportive structure not only play toys, also affecting the exterior of the toys form, function of conversion and product design. When children study the structure of the toy, they can understand the characteristics of the toy, the way of assembly and the diversified play, so as to promote children's observation ability, memory ability and thinking ability.

The Spiel Welle scientific exploration drilling machine (Figure 3), by combining the engineering teaching characteristics of DIY and STEAM, children can

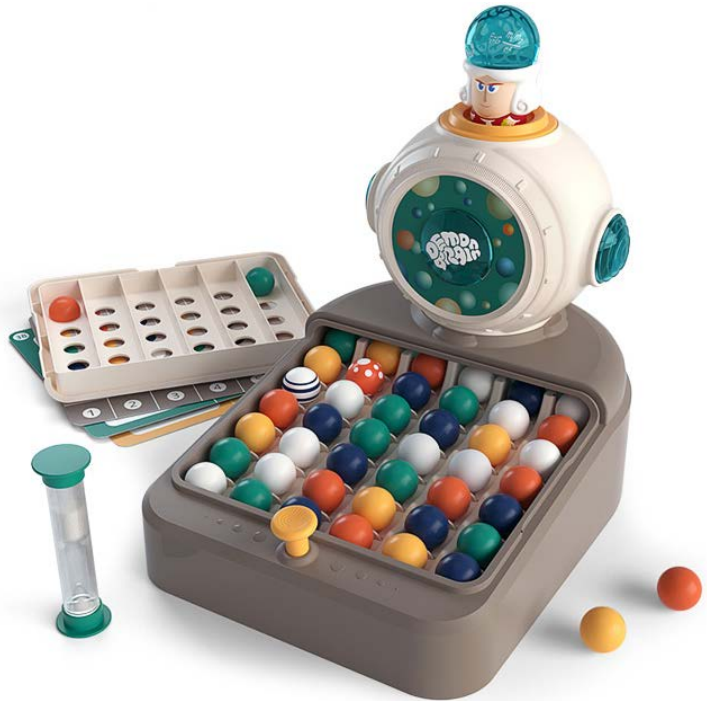

Figure 2. Eliminate ball. 
experience the characteristics and processing methods of materials. Through observation, they can better understand the working process of the driving device and feel the fun of doing things by themselves.

\subsection{Application of New Technologies}

The development of science and technology to promote the development of new technology application and toys in the Internet age, the application of new technology makes the toy variability, the brain waves, $3 \mathrm{G}$ technology, Internet technology and virtual reality VR into toy design, through sound, color, light and other interesting ways, to attract children's attention, online learning, help children develop good study habits, Enhance children's interest in learning to promote participation, interactivity, imagination and innovation.

Handy Block programming blocks (Figure 4), through the materialization of the intelligent building blocks, more than 50 programming instructions will be built, through linkage control robot, and the surrounding things to each other, and give different information feedback, in the process of playing stimulate a

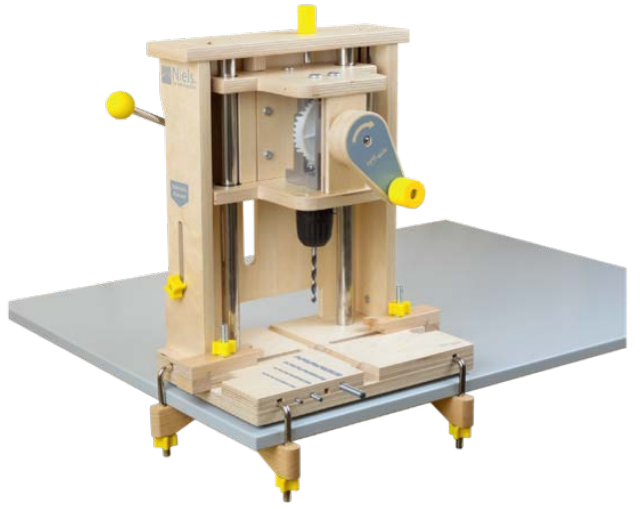

Figure 3. Spiel Welle scientific exploration drilling machine.

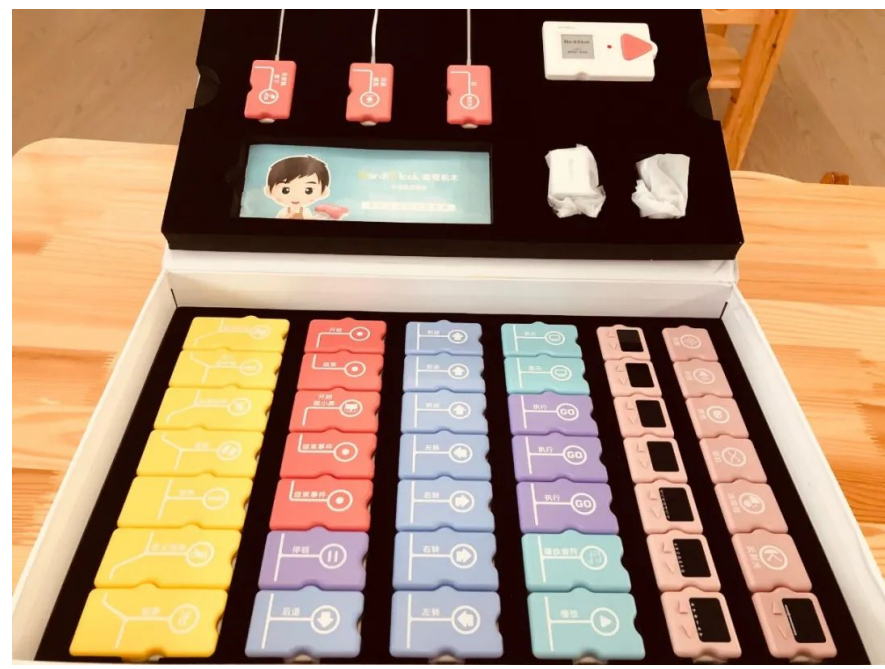

Figure 4. Handy Block programming blocks. 
child's exploratory, cultivate their execution, and give full play to the imagination, let your children play in the construction of knowledge network, Learn to analyze and look at problems with a digital perspective, and apply the knowledge to solve problems.

\subsection{Art and Aesthetics}

Children's art toys, more from the children's feelings of life, the integration of painting, calligraphy, music and other forms, through art to improve the cultivation of children, the development of children's ability to observe, imagination and creativity. Painting toys can exercise children's memory and thinking through observation, enhance children's cultural accumulation and artistic accomplishment, and bring a sense of achievement for children. The art of combining STEAM education with toys can integrate emotion into modern technology through the appearance and decoration of toys, making it easier for children to understand and accept new knowledge.

Such as children's 3D printing pen, children can draw anything they imagine unrestrained, not only can exercise their imagination, but also can cultivate children's expression ability, hands-on ability and the ability to summarize things, so that they can understand and recognize more knowledge in the process of creation.

\section{Conclusion}

Based on STEAM education concept, children's teaching toys integrate diversified subject knowledge, new technology and art, and cultivate children's practical ability, exploration ability and the ability to analyze and solve problems. Let children be able to think comprehensively, learn in play, through this imperceptible way, make learning interesting, cultivate children's ability to take the initiative to learn, so as to deepen the understanding of knowledge. By analyzing the design principles of STEAM teaching assisted toy, this paper proposes a design method for children's educational toys based on STEAM education, which vigorously promotes the development of STEAM education and provides reference directions for toy designers and children's education.

\section{Acknowledgements}

This paper is one of the periodic achievements of the Research Ability Promotion Program for Teachers of Beijing Normal University, Zhuhai (201850008).

\section{Conflicts of Interest}

The author declares no conflicts of interest regarding the publication of this paper.

\section{References}

Liu, Y. T. (2020). How to Improve the Teaching Efficiency of Early Childhood Science 
Activities Based on STEAM Concept. Question and Research, 34, 105-106.

Qin, X. Y., Xu, W., \& Zhan, X. X. (2020). Design of Children's Educational Toys Based on STEAM Education. Furniture and Interior Decoration, 8, 80-82.

Song, Y. J., \& Jiang, X. (2020). Children's Educational Toy Design Trend under STEAM Concept. Design, 33, 134-136.

Yang, C. S., Yang, Y. C., Chen, J. T., Lin, B. T., \& Hu, Y. J. (2014). Emotional Conception in the Design of Intelligent Interactive Toys. Old Building, 12, 38-40.

Yu, X. L. (2016). Exploratory Research on Toy Design Based on Steam Education for Children. Tianjin University of Science and Technology. 